\title{
Chilli-briquettes modify the temporal behaviour of elephants, but not their numbers
}

\author{
Rocío A. Pozo, Tim Coulson, Graham McCulloch \\ AMANDA STRONZA and ANnA SONghurst
}

\begin{abstract}
Crop loss to foraging elephants is one of the most significant causes of conflict between people and elephants in areas where wild elephants share resources with people. Effective solutions to reduce the effects of human-elephant conflict on local livelihoods are thus essential to foster coexistence between elephants and people. We assessed the effectiveness of chilli-briquettes (bricks made of dry chilli, elephant dung and water) in altering elephants use of space in the eastern Okavango Panhandle, Botswana. We burned $>600$ briquettes during the night over a 2-month period to test five treatments: frequent burning of (1) chilli and (2) chilli-free briquettes, occasional burning of (3) chilli and (4) chilli-free briquettes, and (5) a control treatment. Using camera traps and footprint surveys we assessed the number of elephants that used experimental sites, and the times at which they did so. We found elephants changed their movement behaviour from predominantly nocturnal to diurnal in areas where chilli-briquettes were burned throughout the night; however, there was no difference in the mean numbers of individuals between treatments with and without chillies. In other words, chilli-briquettes had a repellent but not a deterrent effect on elephants, keeping them away only at times when chilli-briquettes were smouldering. Based on these findings we recommend the use of chilli-briquettes as a method to deter elephants in the short term. In the long term, chilli-briquettes should be applied in combination with other larger-scale mitigation approaches, such as land management and cooperative community-based tools.
\end{abstract}

Keywords Botswana, chilli peppers, crop foraging, crop raiding, HEC, human-elephant conflict, human-wildlife interactions, Okavango Delta

\section{Introduction}

$\mathrm{D}$ amage or destruction of crops by foraging elephants is one of the most widespread and costly sources of

Rocío A. Pozo ${ }^{\star} \dagger$ (Corresponding author), Tim Coulson, Graham McCulloch ${ }^{\star}$ and Anna Songhurst* Department of Zoology, University of Oxford, The Tinbergen Building, South Parks Road, Oxford, OX1 3PS, UK

E-mail rocio.pozo@zoo.ox.ac.uk

Amanda StronZA* Applied Biodiversity Science Program, Texas A\&M University, College Station, USA

*Also at: Ecoexist Project, Maun, Botswana

$\dagger$ Also at: Biological and Environmental Sciences, University of Stirling, Stirling, UK

Received 26 March 2017. Revision requested 24 May 2017.

Accepted 26 July 2017. First published online 28 November 2017. human-elephant conflict across Africa (Hoare, 2000; Sitati et al., 2003), and is often perceived as a threat to elephant conservation as well as to the livelihoods and wellbeing of local people. The physical (e.g. destruction of crops and property), social (e.g. children missing school because they are guarding fields during the night), economic (e.g. food insecurity) and health (e.g. increased risk of contracting malaria) implications for people living with elephants (Thirgood et al., 2005; Barua et al., 2013) lead to negative attitudes towards elephants, and retaliatory killing of the animals, thus undermining elephant conservation efforts (Nyhus \& Tilson, 2000; Osborn \& Parker, 2003). A key strategy to decrease human-elephant conflict involves developing and testing mitigation strategies to prevent crop foraging by elephants (Naughton et al., 1999; Hoare, 2000). However, few published studies have assessed the performance of elephant deterrents (but see Sitati \& Walpole, 2006; Graham \& Ochieng, 2008; Davies et al., 2011). Here, we tested the effectiveness of one of the most popular forms of elephant deterrent recommended in our study area in Botswana: the burning of chilli-briquettes (bricks made of dry chilli, elephant dung and water).

Elephant deterrents include the use of traditional methods (noise, fire), spotlights, electric and beehive fences, and chilli-pepper (Capsicum spp.) based methods (fences, bombs and briquettes). Since the 1990s the use of chillipeppers as a mitigation method against elephant cropforaging has expanded across Africa and Asia (Osborn \& Rasmussen, 1995; Hedges \& Gunaryadi, 2010). Chillies have low palatability for wildlife (Parker \& Osborn, 2006), can be applied at low cost, and have the added advantage of producing extra income from the sale of chillies for other purposes, which contributes towards improving local livelihoods (Karidozo \& Osborn, 2015). The most common forms of chilli-based deterrents are fences (i.e. poles connected with ropes and pieces of cloth greased with chillies) and briquettes (Hoare, 2012). Although farmers report a preference for chilli fences (Davies et al., 2011; Noga et al., 2015), this method often fails because people are unwilling or financially unable to maintain the fences (Graham \& Ochieng, 2008). In contrast, chilli-briquettes are an affordable option for many subsistence farmers.

The reported success of chilli-based methods varies, with some studies reporting $100 \%$ success (Sitati \& Walpole, 2006; Karidozo \& Osborn, 2015) and others reporting an absence of deterrent effect (Hedges \& Gunaryadi, 2010). This inconsistency may be attributable to methodological and analytical factors (e.g. different experimental designs). 
Firstly, chilli-based methods are often tested in combination with other deterrents (Osborn \& Parker, 2002; Graham \& Ochieng, 2008; Davies et al., 2011), thus rendering the effect of each unclear. Secondly, criteria used to evaluate the effectiveness of deterrents vary considerably across studies, with success being based on the number of crop-foraging events (Sitati \& Walpole, 2006; Graham \& Ochieng, 2008), the area of crops destroyed (Karidozo \& Osborn, 2015), the time lag of elephants' reaction to the effect of chillies (Osborn \& Parker, 2002), or local farmers' perception of effectiveness (Graham \& Ochieng, 2008; Noga et al., 2015).

Botswana has the largest population of African elephants Loxodonta africana (Chase et al., 2016), with northern Botswana holding the highest proportion of elephants in the country (DWNP, 2013). Elephant numbers have increased in recent decades (Songhurst et al., 2016), specifically in areas with permanent sources of water, such as the eastern Okavango Panhandle. In this region, levels of poverty are high (CSO, 2011; Noga et al., 2015) and subsistence agriculture is the main livelihood activity (Songhurst et al., 2016). Local NGOs in collaboration with the government of Botswana have included the use of chilli-based methods in their management plans, and chillies have been the only elephant deterrent recommended in the eastern Panhandle region. Although local people in northern Botswana have a favourable perception of chillies as a deterrent (Noga et al., 2015), the effectiveness of this method has not been tested, despite it being recommended. Evaluation of cropforaging deterrents is important to avoid irreversible consequences of poorly planned conservation management (Webber et al., 2007).

We implemented the first controlled and replicated experimental trial in the region to test the use of chillibriquettes as an elephant deterrent, applying five treatments with and without chillies in the eastern Panhandle during the dry season of 2015. We expected chilli treatments to deter elephants relative to non-chilli treatments. Our experiment has the potential to be widely applied as a non-lethal method in areas where elephants forage on crops, given the low cost and high benefits of growing chillies. Such an assessment and protocol will facilitate the development of novel ways of mitigating pressure on crops, and provides a replicable model for testing effectiveness elsewhere.

\section{Study area}

Our study was conducted between the villages of Seronga and Beetsha in the eastern Okavango Panhandle, northern Botswana (Fig. 1). The area is delimited by the BotswanaNamibia border fence to the north, the Okavango River to the south-west and the Northern Buffalo Fence to the south and east (Fig. 1). The Okavango Delta is formed from the Okavango River that flows from Angola, along the Caprivi
Strip in Namibia, and reaches a tectonic trough in the centre of the Kalahari in Botswana. The Delta has a wet (November-April) and a dry (May-October) season, with annual rainfall of $360-500 \mathrm{~mm}$. Daily temperatures range from $25-35^{\circ} \mathrm{C}$ during the day to a mean of $8^{\circ} \mathrm{C}$ during the night (Ramberg et al., 2006), and the hottest month is October.

The eastern Panhandle has one of the largest populations of elephants in the country, with $>18$,0oo individuals (Songhurst, 2016), who remain close to the river throughout the year (Pozo et al., unpubl. data). This not only impacts the livelihoods of the 16,000 people living along the Okavango River (CSO, 2011; Fig. 1) during the crop-growing months (November-May) but also leads to negative interactions between people and elephants throughout the year. The primary livelihood activity is subsistence agriculture, and farmers harvest their crops during April-June (Songhurst et al., 2016). During this time they use traditional (drums, fire) and non-traditional crop-foraging mitigation methods (chilli fences) to deter elephants from their fields (Noga et al., 2015).

\section{Methods}

\section{Briquettes}

We used 1,176 kg of elephant dung and $235.2 \mathrm{~kg}$ of chilli powder to make 672 briquettes of two types: chilli-briquettes and non-chilli briquettes. For the chilli-briquettes we mixed chilli powder from dry chilli-pepper fruits with crushed elephant dung at a ratio of $1: 2$ (Karidozo \& Osborn, 2015). To create a thick paste we added water to the mix, which was then pressed into moulds of $40 \times 20 \times 15 \mathrm{~cm}$. Once the mixture was set, we removed the moulds and left the briquettes in the sun for a minimum of 2 weeks. We turned over each briquette every second day to make sure they dried evenly. For non-chilli briquettes we repeated the same protocol, replacing the chillies with an equivalent amount of elephant dung. We used separate moulds for each type of briquette to avoid cross-contamination between briquette types.

\section{Experimental design and data collection}

We conducted our experiment during the dry season of 2015, from late September to the beginning of November, when elephants use areas close to the river (Jackson et al., 2008; Pozo et al., unpubl. data). We used satellite tracking data from previous years to identify 10 experimental sites in areas that were used frequently by elephants (Fig. 2). We fitted satellite collars on 10 female and 10 male elephants in April 2014. Each collar was set to record hourly global positioning system coordinates, and the data were used to estimate the utilization distribution 


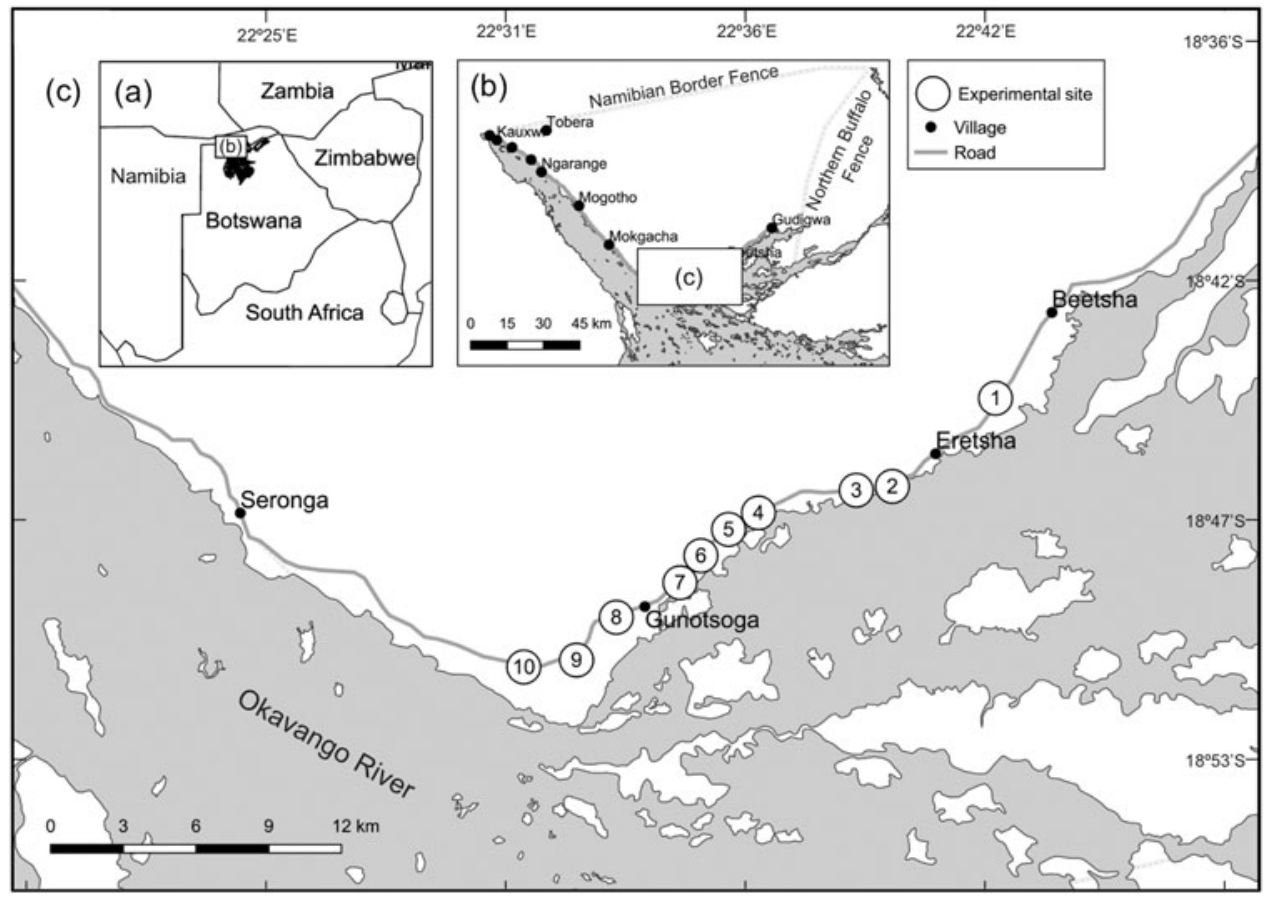

FIG. 1 (a) Location of the eastern Okavango Panhandle in Botswana. (b) Villages along the Okavango River. (c) Location of the experimental sites, between the villages of Seronga and Beetsha. for all individuals. We combined all data collected during the dry seasons of 2014 and 2015 to develop a heat distribution map, which represents the probability of any elephant being present within the study area (Fig. 2).

Each experimental site consisted of a $100 \mathrm{~m}$ transect with a camera trap at either end (hereafter experimental transect), within a surrounding area of $4,000 \mathrm{~m}^{2}$ (hereafter survey area; Fig. 3). As elephants move towards the Okavango River mainly at night, when they adopt safety-in-numbers behaviour (i.e. several herds gather together in larger groups) before crossing the road to access water (Songhurst et al., 2016), we located experimental sites at a maximum of $200 \mathrm{~m}$ from the main road, and parallel to it, to detect as many elephants as possible. In addition, experimental sites were situated outside villages, away from corridors (Songhurst et al., 2016) and at least $1 \mathrm{~km}$ apart to control for variation resulting from cross treatment effects and to maintain spatial independence.

To test the effect of chillies independently from the effect of smoke on elephant trajectories, we applied two treatments every day: chilli $(C$, experimental sites with chillibriquettes), and no chilli (NC, sites with briquettes without chilli). Two additional treatments were used to investigate whether the effect of chillies varied depending on exposure rates: chilli once $(\mathrm{C} 1$, sites with chilli-briquettes lit once per week), and no-chilli once ( $\mathrm{NC} 1$, sites with non-chilli briquettes lit once per week). In parallel to these treatments we ran a control group (i.e. sites without briquettes). Each treatment had two replicates, and therefore 10 experimental sites were established in the field. Briquettes were placed at $20 \mathrm{~m}$ intervals along experimental transects, following
Karidozo \& Osborn (2015), which resulted in six briquettes per transect per night (Fig. 3).

We divided our experimental period into four 2-week blocks (i.e. survey 1, experimental blocks 1 and 2, and survey 2). During surveys 1 and 2 no treatments were implemented. In experimental block 1, all treatments were allocated randomly across sites. Treatments were rerandomized at the start of experimental block 2. Briquettes were lit every day before sunset (17.00-19.00), when elephants move from bush covered areas to the river. Our camera traps detected that briquettes smouldered for 6-7 hours every night. All experimental sites were surveyed the morning after for footprint counts.

We used two methods to estimate the frequency with which elephants visited experimental sites: footprint counts and camera traps (20 camera traps in total). Footprint surveys took place on a daily basis within the $4,000 \mathrm{~m}^{2}$ survey area at each site from week 2 (survey 1 ) to week 7 (survey 2 ). We did not perform footprint surveys in weeks 1 and 8 , but camera traps collected data throughout this period, to consider the effect of disturbance by the principal researcher (RAP) on elephant occurrence. Experimental sites were checked every morning (07.30-09.30), when the risk of encountering elephants in the field was lower. The substrata in the eastern Panhandle are deep Kalahari sands, which facilitate clear identification of footprints. We followed a standardized footprint protocol (Lee \& Moss, 1995) in which RAP and a field assistant visited each site and estimated the number of elephants that had crossed the $4,000 \mathrm{~m}^{2}$ survey area in the previous 24 hours. This was done using ten $40 \mathrm{~m}$ transects separated by $10 \mathrm{~m}$, perpendicular to the $100 \mathrm{~m}$ 


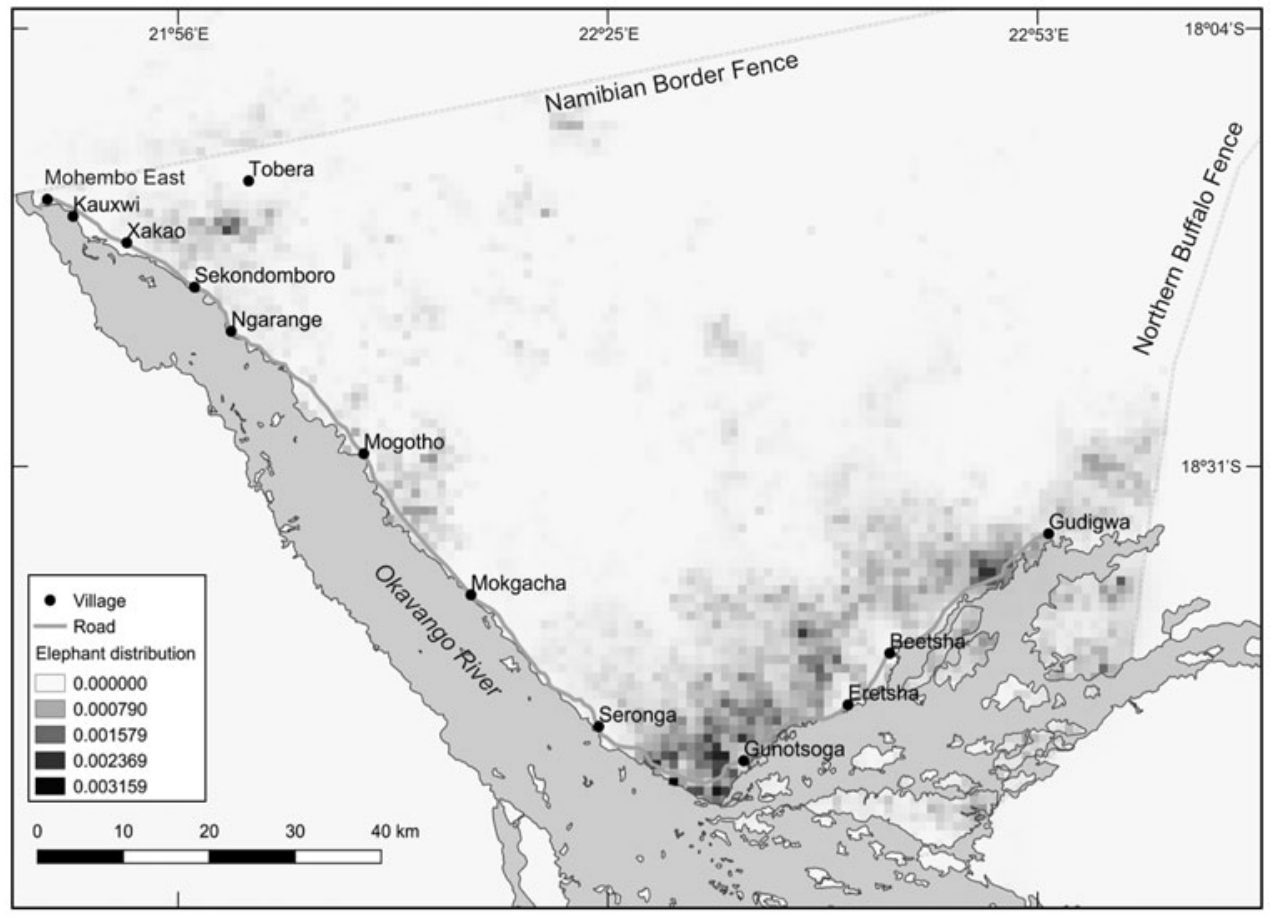

FIG. 2 Dry season (MayOctober) population probability distribution of elephants in the eastern Okavango Panhandle, Botswana (Fig. 1) for 2014 and 2015 combined. Each grid square represents $1 \mathrm{~km}^{2}$. Data were collected during the dry seasons of 2014 and 2015, from 20 satellite-tracked elephants Loxodonta africana collared by the Ecoexist Project. experimental transect (Fig. 3). After every survey, the survey area was cleared using a rake to remove elephant tracks. Two camera traps were located at each end of every experimental transect, facing each other across the transect (Fig. 3). All cameras were set on trees, at least $1 \mathrm{~m}$ above the ground, and were programmed to take three photographs per trigger throughout the day and night. We used a combination of Night Vision Infrared Trophy Cam HD (Bushnell, Overland Park, USA) and HC50o (Reconyx, Inc., Holmen, USA) cameras. Both models use infrared flashes that cause minimal disturbance to elephants during the night. From the time stamp on camera-trap photographs we were able to ascertain the exact time elephants visited experimental sites.

\section{Statistical analysis}

We recorded the number of elephants at experimental sites using both footprint surveys and camera-trap images. The data collected through both methods differed in format, making it difficult to combine them. Consequently, to investigate the occurrence of elephants we used footprint surveys, and to assess elephants' temporal use of the study area we used camera-trap data.

We analysed the occurrence of elephants across experimental sites as the mean number of elephants per day per transect per treatment. Each mean provided an estimate of elephant space-use per day at each treatment, and an efficient way of dealing with spatial pseudoreplication
(Crawley, 2007) at experimental sites. We modelled mean number of elephants as a function of treatment type and transect identity using linear models. We included the effect of 'transect' to measure the response of elephants to the specific site location. In this way we accounted for environmental variation between sites, which could otherwise affect the outcome of our treatments. In addition, in our study area elephants usually prefer habitats with proximity to water (Loarie et al., 2009), and they avoid areas occupied by people (Songhurst et al., 2016). Therefore, we also included in our analysis the effect of the distance between experimental sites and the nearest settlement (including houses outside villages) and water sources (waterholes and/or the Okavango River). Our final linear model included the mean number of elephants as a function of treatment, transect identity, and distance to water and to the nearest settlement. Model selection was based on the lowest value of Akaike's Information Criterion (AIC; Akaike, 1973), considering $\triangle$ AIC $>2$ to represent significantly different models (Burnham \& Anderson, 2002). We used the dredge function in the MuMIn package in R. v. 3.o.1 (R Development Core Team, 2014) to run models with all possible combinations of factors.

We investigated elephants' temporal use of the survey areas using the camera-trap data to detect if the use of chilli-briquettes changed the timing of elephant activity. To examine whether the proportion of elephant photographs changed within 24 hours across the various treatments we split each day into 'day' (06.00-18.00) and 'night' (18.00-06.00), following Loarie et al. (2009). In the 


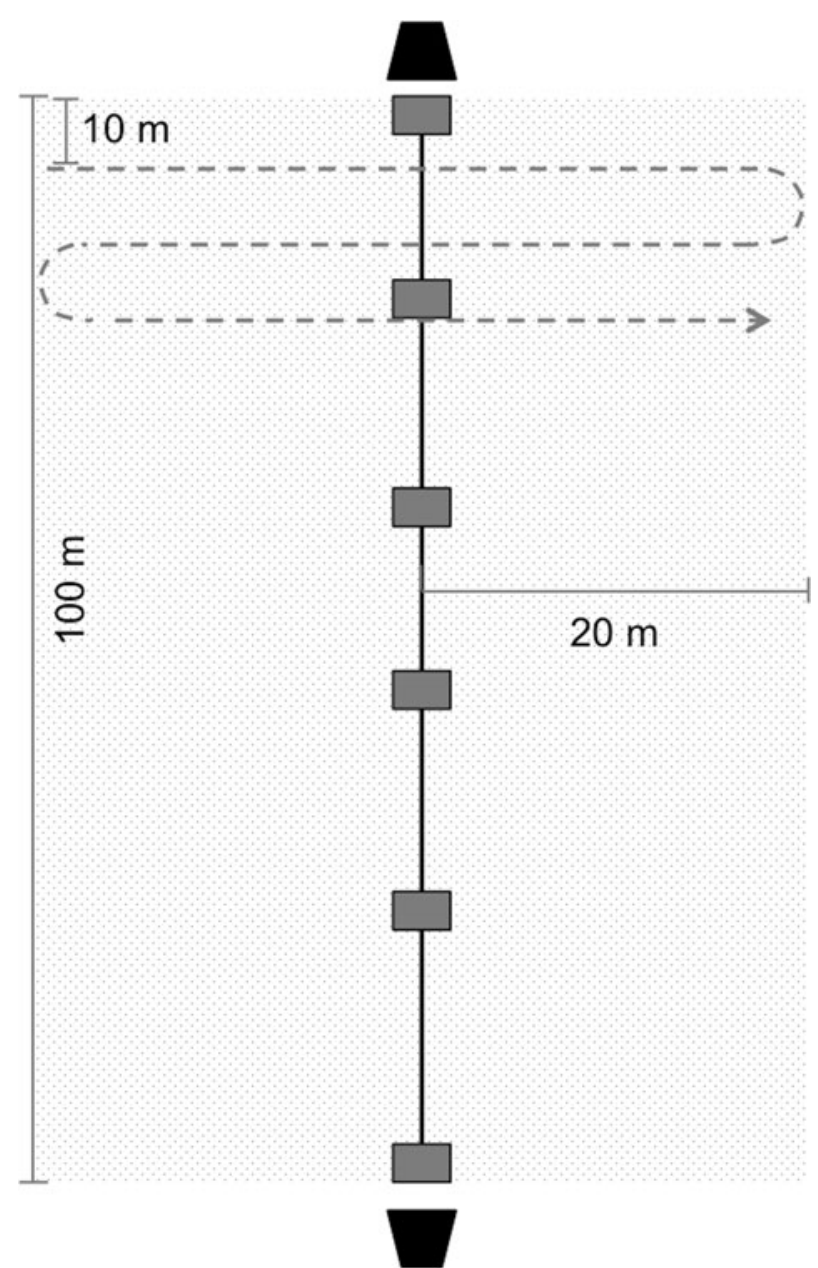

FIG. 3 Experimental site design, with a $100 \mathrm{~m}$ transect (vertical black line) with camera traps (black trapezoids) at either end, and briquettes (grey rectangles) at $20 \mathrm{~m}$ intervals. The dotted area denotes the $4,000 \mathrm{~m}^{2}$ survey area, and the dashed grey arrow crossing the survey area represents $40 \mathrm{~m}$ transects used in the footprint survey.

eastern Panhandle elephants are more active during the night, when they move towards the river (Jackson et al., 2008). Thus, we analysed the proportion of elephant photographs taken during the night $(y=$ two column object containing the counts of night and day images) per transect per treatment, using generalized linear models with quasibinomial errors and a logit link function because of data overdispersion. We built the models with the proportion of elephant photographs taken during the night as a function of treatment and transect identity. For all statistical analysis we used $R$ v. 3.o.1.

\section{Results}

The mean number of elephants did not vary across chilli treatments $\left(\mathrm{C}\right.$ and $\left.\mathrm{C}_{1}\right)$ in relation to non-chilli treatments $(\mathrm{NC}$, $\mathrm{NC} 1$ and control). The best model to explain the mean number of individuals observed per day in our footprint survey included the additive effects of treatment and transect location (Table 1 ; AIC = 136.4). Although there was a negative effect of chillies on the number of elephants, the mean number of individuals in experimental sites was not statistically different for chilli (C: $-7.15 \pm S E 5.29, P>0.1$; C1: $-4.49 \pm$ SE 6.02, $\mathrm{P}>0.1$ ) and non-chilli treatments (NC: $1.42 \pm \mathrm{SE} 6.47$, $\mathrm{P}>0.1$;C1: $-7.79 \pm$ SE 7.09, $\mathrm{P}>0.1$ ). Therefore, the difference in number of elephants crossing experimental sites was equally attributable to variation across treatments and transect identity (Table 1; Fig. 4). To identify the effects of transect identity on treatments, we also assessed the relation between transect location and distance to nearest settlement and water sources in our analysis. However, we found that the effects of treatments and transects were greater than those of distance to both settlements and water (Table 1).

The camera-trap data supported our survey results, showing the proportion of elephant photographs captured during the night was influenced by treatment and transect location (Table 1; AIC = 208.1). We found the number of elephants captured during the night at chilli and non-chilli sites to be smaller than for the control group (Fig. 5). Moreover, the proportion of photographs taken at night was smaller for chilli (C: $-3.58 \pm$ SE 1.63, P < 0.1; C1: $-3.66 \pm$ SE 0.74, P > 0.1) than for non-chilli treatments (NC: $-2.3 \pm$ SE 2.75, P > 0.1; NC1: $-3.32 \pm$ SE 2.85, P > 0.1) (Fig. 5).

Overall, chilli-briquettes altered elephants' temporal behaviour during our experiment (although not significantly), keeping elephants away from sites with chilli treatments at night. However, chilli-briquettes did not affect the mean number of elephants crossing sites throughout a 24-hour period. In other words, herds stayed away from chillibriquettes only during times when they were smouldering, and therefore a similar number of elephants crossed chilli sites everyday but at times when briquettes were not burning.

\section{Discussion}

In the short term, burning chilli-briquettes changes the timing of elephant visits to a given area. However, it does not significantly alter the number of elephants occurring in a specific area over a 24-hour period (Graham \& Ochieng, 2008; Graham et al., 2009; Hoare, 2012). Thus, chillies have a repellent but not necessarily a deterrent effect on elephants (Osborn \& Rasmussen, 1995). Our unique controlled and replicated experimental design is the first to show that chilli-briquettes change the temporal behaviour of elephants by keeping them away during hours when the pungent effect of chillies is present. We therefore recommend the use of chilli-briquettes at night-time, when the risk posed by elephants to people and property is higher (Chiyo \& Cochrane, 2005), to obtain rapid results that will alleviate immediate impacts on crops by deterring elephants in the short term. 
TABLE 1 Summary of footprint and camera-trap model selection based on Akaike's Information Criterion (AIC), with $\Delta$ AIC (the difference between each model and the best model selected) and weight (the relative likelihood of each model). AIC was used to evaluate relationships of the mean number of elephants Loxodonta africana (footprint survey) and proportion of elephant photographs (camera-trap survey) with five explanatory variables: transect identity (transect), distance to people's settlements (people), experimental treatment (treatment), villages (village) and water sources (water).

\begin{tabular}{|c|c|c|c|c|c|c|c|c|c|}
\hline \multirow[b]{2}{*}{ Model } & \multicolumn{6}{|c|}{ Explanatory variables } & \multirow[b]{2}{*}{ AIC } & \multirow[b]{2}{*}{$\Delta \mathrm{AIC}$} & \multirow[b]{2}{*}{ Weight } \\
\hline & Intercept & Transect & People & Treatment & Village & Water & & & \\
\hline \multicolumn{10}{|c|}{ Footprint survey } \\
\hline Model 1 & 4.70 & + & & + & & & 136.4 & 0.0 & 0.113 \\
\hline Model 2 & 1.83 & + & & & & & 140.9 & 4.6 & 0.012 \\
\hline Model 3 & -6.11 & & 47.87 & & & & 151.0 & 14.7 & 0 \\
\hline Model 4 & 0.58 & & 44.04 & & -1.50 & & 151.8 & 15.5 & 0 \\
\hline Model 5 & -10.88 & & 53.29 & & & 2.48 & 152.6 & 16.3 & 0 \\
\hline Model 6 & -1.58 & & 46.16 & & -1.37 & 0.82 & 153.8 & 17.4 & 0 \\
\hline Model 7 & 8.80 & & 45.25 & + & -2.81 & & 155.5 & 19.1 & 0 \\
\hline Model 8 & -3.60 & & 50.92 & + & & & 156.5 & 20.1 & 0 \\
\hline Model 9 & 15.26 & & 39.31 & + & -3.28 & -2.33 & 157.2 & 20.8 & 0 \\
\hline Model 10 & 28.12 & & & & -3.06 & -5.62 & 157.5 & 21.2 & 0 \\
\hline Model 11 & 19.72 & & & & -2.50 & & 157.6 & 21.2 & 0 \\
\hline Null & 10.83 & & & & & & 157.9 & 21.5 & 0 \\
\hline Model 12 & -5.90 & & 53.55 & + & & 1.23 & 158.4 & 22.0 & 0 \\
\hline Model 13 & 15.18 & & & & & -3.79 & 159.0 & 22.7 & 0 \\
\hline Model 14 & 42.59 & & & + & -5.19 & -8.38 & 160.1 & 23.7 & 0 \\
\hline Model 15 & 28.89 & & & + & -4.12 & & 162.9 & 26.5 & 0 \\
\hline Model 16 & 13.46 & & & + & & & 165.0 & 28.7 & 0 \\
\hline Model 17 & 19.95 & & & + & & -5.62 & 165.3 & 28.9 & 0 \\
\hline \multicolumn{10}{|c|}{ Camera-trap survey } \\
\hline Model 1 & 0.93 & + & & + & & & 208.1 & 0 & 1 \\
\hline Model 2 & -2.02 & + & & & & & 546 & 337.9 & 0 \\
\hline Model 3 & 3.21 & & & + & & & 674.1 & 446.9 & 0 \\
\hline Model 4 & 0.41 & & & & & & $1,166.7$ & 958.6 & 0 \\
\hline
\end{tabular}

Crop-foraging by elephants is a significant challenge for subsistence farmers. Finding effective ways to deter elephants from fields can help strengthen food security, reduce conflicts with elephant conservation, and improve local perceptions of elephants (Davies et al., 2011). Testing mitigation methods in the field is key to ensuring their effectiveness and feasibility. Despite this, our understanding of the effectiveness of elephant crop-foraging deterrents is limited because of the absence of controlled trials and published studies on their exclusive use (Graham et al., 2009). In this context, we implemented a controlled and replicated experiment to test the most popular form of chilli deterrent recommended in our study area. We controlled for environmental variation between experimental sites, assigning them to areas away from villages and outside elephant corridors, as well as controlling for the distances between experimental sites and the main road. In addition, and in contrast to other studies, we did not enlist the help of farmers to implement our experiment, as we wished to ensure our experimental protocol was efficient before recommending it to local communities. We did not perform our experiment during the harvesting season, as we aimed to decrease bias associated with the palatability of crops in experimental trials, as well as inconsistent experimental protocols. RAP, in collaboration with two local assistants, built and smouldered briquettes throughout the experiment, to ensure continuity and consistency. Each site followed the same protocol and had the same level of effort (which also made random selection of experimental sites possible).

Despite the efforts to implement a controlled experiment, the spatial distribution of elephants as well as their temporal movement had a considerable influence on the performance of treatments relative to experimental sites. Previous studies of chilli-based approaches have faced similar challenges; for example, studies have concluded that the overall decline in crop-foraging recorded may have been a result of increased rainfall (Sitati \& Walpole, 2006), or other unmeasured environmental factors (Osborn \& Parker, 2002). Therefore, it would be useful for future studies to clarify to what extent environmental variation, and its effect on elephant movement, affect the performance of chilli deterrents.

The change in elephants' temporal behaviour and the decrease in the number of elephants crossing chilli sites, although not significant, are indicators that chilli-briquettes are an effective method to modulate elephant trajectories 

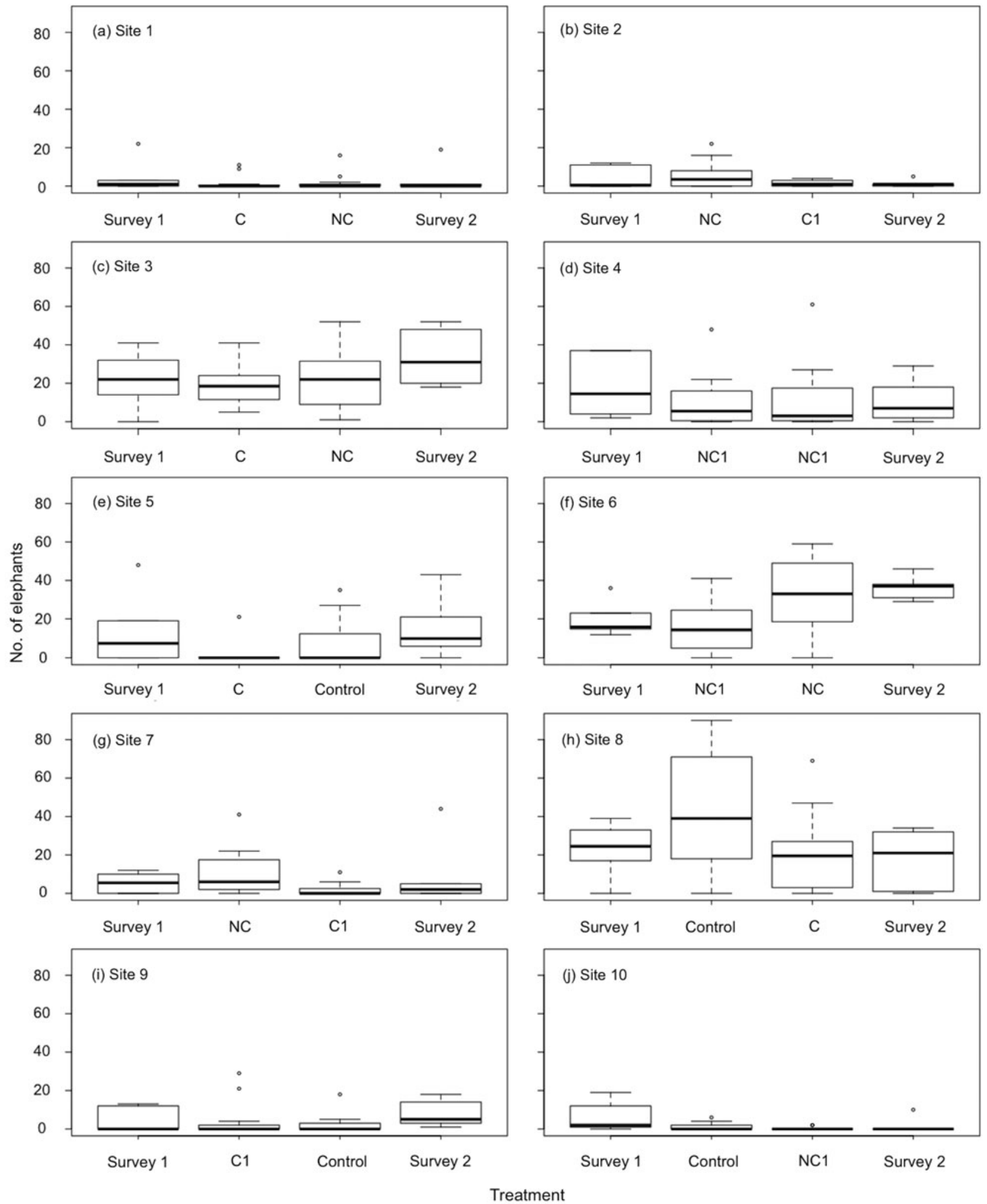

FIG. 4 Box plots of the number of elephants per transect per treatment, at 10 experimental sites in the eastern Okavango Panhandle, Botswana (Fig. 1C). In surveys 1 and 2 no treatments were implemented, and in the two experimental blocks between the surveys five treatments were implemented randomly across sites: chilli-briquettes lit every day (C), chilli-briquettes lit once per week (C1), non-chilli briquettes lit every day $(\mathrm{NC})$, non-chilli briquettes lit once per week (NC1), and a control group. 


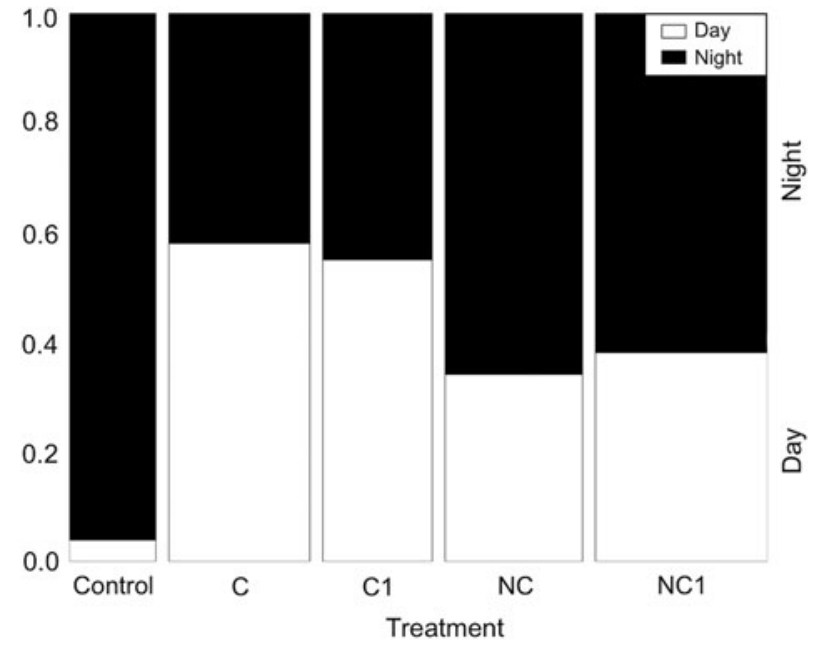

FIG. 5 Temporal distribution of elephant photographs per treatment (Control; C, chilli-briquettes lit every day; $\mathrm{C}$, chilli-briquettes lit once per week; NC, non-chilli briquettes lit every day; $\mathrm{NC} 1$, non-chilli briquettes lit once per week). The width of each bar represents the number of elephant photographs taken.

during harvesting seasons. Finding effective crop-foraging deterrents for intelligent and social animals such as elephants is particularly challenging. Elephants' communication and cognitive skills, in combination with their large body size and dietary and behavioural flexibility (O'Connell-Rodwell et al., 2000), make them adaptable and successful at foraging crops (Chiyo \& Cochrane, 2005). Previous studies have shown that elephants are able to find alternative ways to forage fields, either by avoiding deterrents or learning from other members of the group (Chiyo \& Cochrane, 2005). However, their sophisticated learning skills can also be part of the solution. Our findings suggest that in a short period of time (i.e. 2 weeks), elephants identified not only the location but also the time at which chilli-briquettes were smouldering, and as a response modified their movement patterns to cross chilli sites either before or after the presence of chilli smoke. This indicates that in the short term chilli-briquettes may trigger a rapid and effective behavioural response by elephants, which will ultimately also increase the likelihood of safer areas for people.

We tested chilli-briquettes for a relatively short period of time, which could be a weakness in our experiment in comparison with previous studies (Graham et al., 2009). However, we conducted our experiment during the dry season, when elephant densities are highest in the study area. Despite any effects of elephant grouping (e.g. elephants' closeness to the river; elephant risk-avoidance aggregations near the main road), we demonstrated that the chillibriquettes had a repellent effect.

Nevertheless, because of the short-term effect of chillibriquettes, as a stand-alone solution they are unlikely to be effective in the long term. Integrated or rotated interventions have a greater chance of success than a single approach on its own (Osborn \& Parker, 2003; Sitati \& Walpole, 2006; Hedges \& Gunaryadi, 2010). Land-use planning, protection of elephant corridors, buffer zone plantations and cooperative community-based tools are some examples that have been suggested to improve coexistence between people and elephants (Parker \& Osborn, 2006; Jackson et al., 2008). The appropriate combination of methods will depend on the specific dynamics of elephant cropforaging in a given location. For the particular case of the eastern Panhandle, we recommend the use of chillibriquettes, in addition to mitigation strategies already in place, because of their rapid repellent effect on elephants. In addition, people in the region have positive perceptions of chillies, and the plants have potential as an alternative source of livelihood for local farmers (Noga et al., 2015).

\section{Acknowledgements}

We thank the Ecoexist Project and the Government of Botswana for facilitating data collection; J. Cusack and K. Karundu, who made the completion of this experiment possible; and P. Lee, G. Shannon and S. Canney for providing valuable comments. This project was funded by the Ecoexist Project and the Chilean National Commission for Scientific and Technological Research (PAI/INDUSTRIA 79090016). Additional support was granted by Kellogg College and the Department of Zoology, University of Oxford, UK.

\section{Author contributions}

RAP and TC conceptualized the study, and collected and analysed the data. All authors contributed to designing the experiment, funding the project and writing the article.

\section{References}

Aкалке, H. (1973) Information theory and an extension of the maximum likelihood principle. In Second International Symposium on Information Theory (eds B.N. Petrov \& F. Csaki), pp. 267-281. Academiai Kiado, Budapest, Hungary.

Barua, M., Bhagwat, S.A. \& Jadhav, S. (2013) The hidden dimensions of human-wildlife conflict: health impacts, opportunity and transaction costs. Biological Conservation, 157, 309-316.

Burnham, K.P. \& Anderson, D.R. (2002) Model Selection and Multimodel Inference, and edition. Springer, New York, USA.

Chase, M.J., Schlossberg, S., Griffin, C.R., Bouché, P.J.C., Duene, S.W., Elkan, P.W. et al. (2016) Continent-wide survey reveals massive decline in African savannah elephants. Peer J, 4, e2354, http://dx.doi.org/10.7717/peerj.2354.

Chiyo, P.I. \& Cochrane, E.P. (2005) Population structure and behaviour of crop-raiding elephants in Kibale National Park, Uganda. African Journal of Ecology, 43, 233-241.

Crawley, M.J. (2007) The R Book. John Wiley and Sons Ltd, Chichester, UK. 
CSO (Central Statistics Office) (2011) Population and housing census. Ministry of Finance and Development Planning, Central Statistics Office, Government of Botswana, Gaborone, Botswana.

Davies, T.E., Wilson, S., Hazarika, N., Chakrabarty, J., Das, D. Hodgson, D.J. \& Zimmermann, A. (2011) Effectiveness of intervention methods against crop-raiding elephants. Conservation Letters, 4, 346-354.

DWNP (Department of Wildlife and National Parks) (2013) Aerial Census of Animals in Northern Botswana, Dry Season 2013. Department of Wildlife and National Parks (DWNP), Government of Botswana, Gaborone, Botswana.

Graham, M.D., Nyumba, T.O., Kahiro, G., Ngotho, M. \& Adams, W.M. (2009) Trials of Farm-based Deterrents To Mitigate Crop-raiding by Elephants Adjacent to the Rumuruti Forest in Laikipia, Kenya. Laikipia Elephant Project, Nanyuki, Kenya.

Graham, M.D. \& Ochieng, T. (2008) Uptake and performance of farm-based measures for reducing crop raiding by elephants Loxodonta africana among smallholder farms in Laikipia District, Kenya. Oryx, 42, 76-82.

Hedges, S. \& Gunaryadi, D. (2010) Reducing human-elephant conflict: do chillies help deter elephants from entering crop fields? Oryx, 44, 139-146.

Hoare, R. (2000) African elephants and humans in conflict: the outlook for co-existence. Oryx, 34, 34-38.

HOARE, R. (2012) Lessons from 15 years of human-elephant conflict mitigation: management considerations involving biological, physical and governance issues in Africa. Pachyderm, 51, 60-74.

Jackson, T.P., Mosojane, S., Ferreira, S.M. \& van Aarde, R.J. (2008) Solutions for elephant Loxodonta africana crop raiding in northern Botswana: moving away from symptomatic approaches. Oryx, 42, 83-91.

Karidozo, M. \& Osborn, F.V. (2015) Community based conflict mitigation trials: results of field tests of chilli as an elephant deterrent. Journal of Biodiversity \& Endangered Species, 3, 144, http://dx.doi.org/10.4172/2332-2543.1000144.

Lee, P.C. \& Moss, C.J. (1995) Structural growth in known-age African elephants (Loxodonta africana). Journal of Zoology, 236, 29-41.

Loarie, S.R., Van Aarde, R.J. \& Pimm, S.L. (2009) Fences and artificial water affect African savannah elephant movement patterns. Biological Conservation, 142, 3086-3098.

Naughton, L., Rose, R. \& Treves, A. (1999) The Social Dimensions of Human-Elephant Conflict in Africa: A Literature Review and Case Studies From Uganda and Cameroon. A Report to the African Elephant Specialist, Human-Elephant Conflict Task Force. IUCN, Gland, Switzerland.

Noga, S.R., Kolawole, O.D., Thakadu, O. \& Masunga, G. (2015) Small farmers' adoption behaviour: uptake of elephant crop-raiding deterrent innovations in the Okavango Delta, Botswana. African Journal of Science, Technology, Innovation and Development, 7, 408-419.

Nyhus, P.J. \& Tilson, R. (2000) Crop-raiding elephants and conservation implications at Way Kambas National Park, Sumatra, Indonesia. Oryx, 34, 262-274.

O’Connell-Rodwell, C.E., Rodwell, T., Rice, M. \& Hart, L.A. (2000) Living with the modern conservation paradigm: can agricultural communities co-exist with elephants? A five-year case study in East Caprivi, Namibia. Biological Conservation, 93, 381-391.

Osborn, F.V. \& Parker, G.E. (2002) Community-based methods to reduce crop loss to elephants: experiments in the communal lands of Zimbabwe. Pachyderm, 33, 32-38.

Osborn, F.V. \& PARKer, G.E. (2003) Towards an integrated approach for reducing the conflict between elephants and people: a review of current research. Oryx, 37, 80-84.

Osborn, F.V. \& Rasmussen, L.E.L. (1995) Evidence for the effectiveness of an oleo-resin capsicum aerosol as a repellent against wild elephants in Zimbabwe. Pachyderm, 20, 55-64.

Parker, G.E. \& Osborn, F.V. (2006) Investigating the potential for chilli Capsicum spp. to reduce human-wildlife conflict in Zimbabwe. Oryx, 40, 343-346.

Ramberg, L., Hancock, P., Lindholm, M., Meyer, T., Ringrose, S., Sliva, J. et al. (2006) Species diversity of the Okavango Delta, Botswana. Aquatic Sciences, 68, 310-337.

R Development Core Team (2014) R: A Language and Environment for Statistical Computing. R Foundation for Statistical Computing, Vienna, Austria. Http://www.R-project.org/.

Sitati, N.W. \& Walpole, M.J. (2006) Assessing farm-based measures for mitigating human-elephant conflict in Transmara District, Kenya. Oryx, 40, 279-286.

Sitati, N.W., Walpole, M.J., Smith, R.J. \& Leader-Williams, N. (2003) Predicting spatial aspect of human-elephant conflict. Journal of Applied Ecology, 40, 667-677.

Songhurst, A. (2016) Dry Season Elephant Population Survey Report, Okavango Panhandle, Botswana. Ecoexist Project, Maun, Botswana.

Songhurst, A., McCulloch, G. \& Coulson, T. (2016) Finding pathways to human-elephant coexistence: a risky business. Oryx, 50, 713-720.

Thirgood, S., Woodroffe, R. \& Rabinowitz, A. (2005) The impact of human-wildlife conflict on human lives and livelihoods. In People and Wildlife: Conflict or Coexistence? (eds R. Woodroffe, S. Thirgood \& A. Rabinowitz), pp. 13-26. Cambridge University Press, Cambridge, UK.

Webber, A.D., Hill, C.M. \& Reynolds, V. (2007) Assessing the failure of a community-based human-wildlife conflict mitigation project in Budongo Forest Reserve, Uganda. Oryx, 41, 177-184.

\section{Biographical sketches}

Rocío Pozo is a conservation biologist interested in conflicts in conservation, and particularly wildlife management and its implications for local communities. TIM Coulson is a quantitative ecologist with research interests in conservation, wildlife management and population biology. Graham MCCulloch is an ecologist and biodiversity specialist with a particular interest in the sustainable management of biodiversity inside and outside protected areas. AMANDA STRONZA is an environmental anthropologist with research interests in community-based conservation, ecotourism and sustainable development. Anna Songhurst is a conservation biologist interested in the conservation and management of wildlife, in particular elephants. 